\title{
Experimental and clinical evaluation of an absorbable biomaterial inducing an anti-adhesive barrier (Divide ${ }^{\circledR}$ )
}

\author{
M. Merle · B. Lallemand · A. Lim • \\ G. Gantois
}

Received: 27 November 2007/ Accepted: 20 December 2007/Published online: 13 March 2008

(C) The Author(s) 2008

\begin{abstract}
We evaluated the efficacy of a biomaterial composed of oxidised regenerated cellulose (Divide) in decreasing the formation of peri-tendinous adhesions in an experimental and clinical study. The experimental study was carried out in 47 New Zealand white rabbits whose Achilles tendons were subjected to a crush injury. The left Achilles tendon served as a control, while the right tendon was wrapped in a sheet of Divide ${ }^{\circledR}$. Six weeks later the range of motion at the ankle was measured, the tendons were histologically analysed for peri-tendinous adhesions, the tendon sheath was examined using a scanning electron microscope for determining resorption of the biomaterial and the mechanical properties evaluated. The clinical study was performed on 22 patients; 16 requiring post-traumatic extensor tenolysis and six who underwent dorsal synovectomy for rheumatoid arthritis. A sheet of Divide ${ }^{\circledR}$ was placed either between the periosteum and the tendon or around the tendon in all patients. Total active motion and grip strength was evaluated in all patients pre-operatively
\end{abstract}

M. Merle $(\square) \cdot$ B. Lallemand

Institut Européen de la Main, Nancy, Luxembourg, 13 rue Blaise

Pascal, 54320 Maxéville-Nancy, France

e-mail: mmerle@pt.lu

M. Merle · A. Lim · G. Gantois

Institut Européen de Biomatériaux et de Microchirurgie,

Université Henri Poincaré, B.P. 239,

54506 Vandoeuvre-lès-Nancy Cedex, France

\section{A. Lim}

Hand and Reconstructive Microsurgery,

National University Hospital,

Department of Orthopaedic Surgery,

Yong Loo Lin School of Medicine,

National University of Singapore,

5 Lower Kent Ridge Rd, Singapore, Singapore 119074 and at regular intervals post-operatively. The experimental study showed that ankle range of motion was similar between the control and Divide ${ }^{\circledR}$ treated groups in two rabbits, better in the Divide ${ }^{\circledR}$ group in seven rabbits and better in the control group in two rabbits. The results were not statistically significant $(P \leq 0.262)$ since the numbers were quite low. Histological analysis showed that the treated tendon had a better gliding surface and minimal inflammation/reaction compared to the control group. Scanning electron microscopy on the 10th post-operative day revealed the formation of a new tendon sheath in the Divide $^{\circledR}$ group. The mechanical properties of both the control and experimental Achilles tendon were similar and comparable to a human tendon. The clinical study demonstrated that Divide ${ }^{\circledR}$ was completely resorbed, perfectly biocompatible and non-allergenic. The mean T.A.M. improved from $159.4^{\circ}$ to $187.3^{\circ}(P \leq 0.074)$ and grip strength from $-26.7 \mathrm{kgF}$ to $10.7 \mathrm{kgF}$ on the 84 th post-op day in the extensor tenolysis group (16 digits), while mean return of function to pre-operation level was achieved at 42nd post-operative day and grip strength increased from $-3.4 \mathrm{kgF}$ in the immediate, post-operative period to $+5.7 \mathrm{kgF}$ at the 84 th day in the rheumatoid arthritis group.

\section{Introduction}

Tendon surgery continues to present difficulties because of the risk of adhesions, especially in cases following crush injuries or following extensive synovectomy for rheumatoid arthritis. A number of investigators have focused on the development of biologic substances that might aid in reducing adhesion formation following tendon surgery. However, it has been difficult to obtain objective evidence 
of the efficacy of such biomaterials. It is difficult to compare two patients even if the level and organic nature of injury are apparently identical, because the process of healing is an individual factor.

In 1988, we developed an experimental protocol to objectively evaluate biomaterials with the potential to decrease peri-tendinous adhesions [1]. This protocol is based on comprehensive evaluation of a rabbit Achilles tendon repair and comprises a functional evaluation of the range of motion of the rabbit ankle, a histological study, a study of the tendon surface using a scanning electronic microscope and an evaluation of the mechanical properties of the tendon after treatment. We have previously used this protocol to assess biomaterials like bovine pericardium, Silastic ${ }^{\circledR}$, collagenous Vicryl ${ }^{\circledR}$, Gore-Tex ${ }^{\circledR}$ and Adcon- $\mathrm{T}^{\circledR}[1-3]$ The same protocol was used in this study to evaluate the effectiveness of Divide ${ }^{\circledR}$ which is an absorbable adhesion barrier prepared by the oxidation of regenerated cellulose. This biomaterial has been used in gynaecological surgery since 1990 under the commercial name of Interceed $^{\circledR}[4,5]$.

Based on the results of the experimental study, we received authorisation from the Local Research Ethics Committee to carry out a clinical series among 22 patients evaluated over a 12-week period. Two groups of patients were studied, one comprising of six patients with rheumatoid arthritis who underwent extensor tendon synovectomy. The other group consisted of 16 patients who underwent extensor tendon tenolysis for a stiff digit resulting from an extensor tendon lesion. This study was limited to extensor tendon pathology because the sheet of Divide ${ }^{\circledR}$ cannot be introduced under the pulleys of the flexor tendons in zone 2.

\section{Materials and methods}

\section{Experimental study}

\section{Materials}

Divide $^{\circledR}$ is a sterile, absorbable adhesion barrier prepared by the oxidation of regenerated cellulose. According to the manufacturer (Mitek, J\&J Company), it has many unique mechanical qualities: it cuts without fraying; it adheres to wet tissue (no need to suture it); it does not support bacterial growth, and it elicits a very minimal foreign body response (low inflammatory response and minimal tissue reaction).

\section{Methods}

Surgical procedure About 47 adult New Zealand white rabbits of average weight of $3.2 \mathrm{~kg}$ were used in this study. The rabbit Achilles tendon was chosen because it has a similar diameter to the human flexor tendon. All animals underwent the same surgical procedure as described below and all operations were performed under sterile conditions by the same surgeon (M. M.). The rabbits were anesthetised with an intramuscular injection of ketamine $(100 \mathrm{mg} /$ $\mathrm{kg})$ and acepromazine $(0.2 \mathrm{mg} / \mathrm{kg})$. Anaesthesia was maintained with an intravenous injection of ketamine. Both lower limbs were shaved and prepared with chlorhexidine solution. A longitudinal skin incision was made on the postero-lateral border of the Achilles tendon and both the Achilles tendons were exposed. Haemostasis was maintained with a bipolar coagulator. It was decided to functionally evaluate the rabbit ankle after a severe crushing rather than after suture of tendon laceration. A formal tendon repair needs immoblisation of the rabbit hind limb in a cast and we noted a high incidence of complications (rupture, rabbit eating the plaster cast, pressure sore, infection, etc.) following immobilisation of the rabbit limb. Three clamps (Kocher forceps) were applied on the two tendons for 20 min (Fig. 1a) to simulate

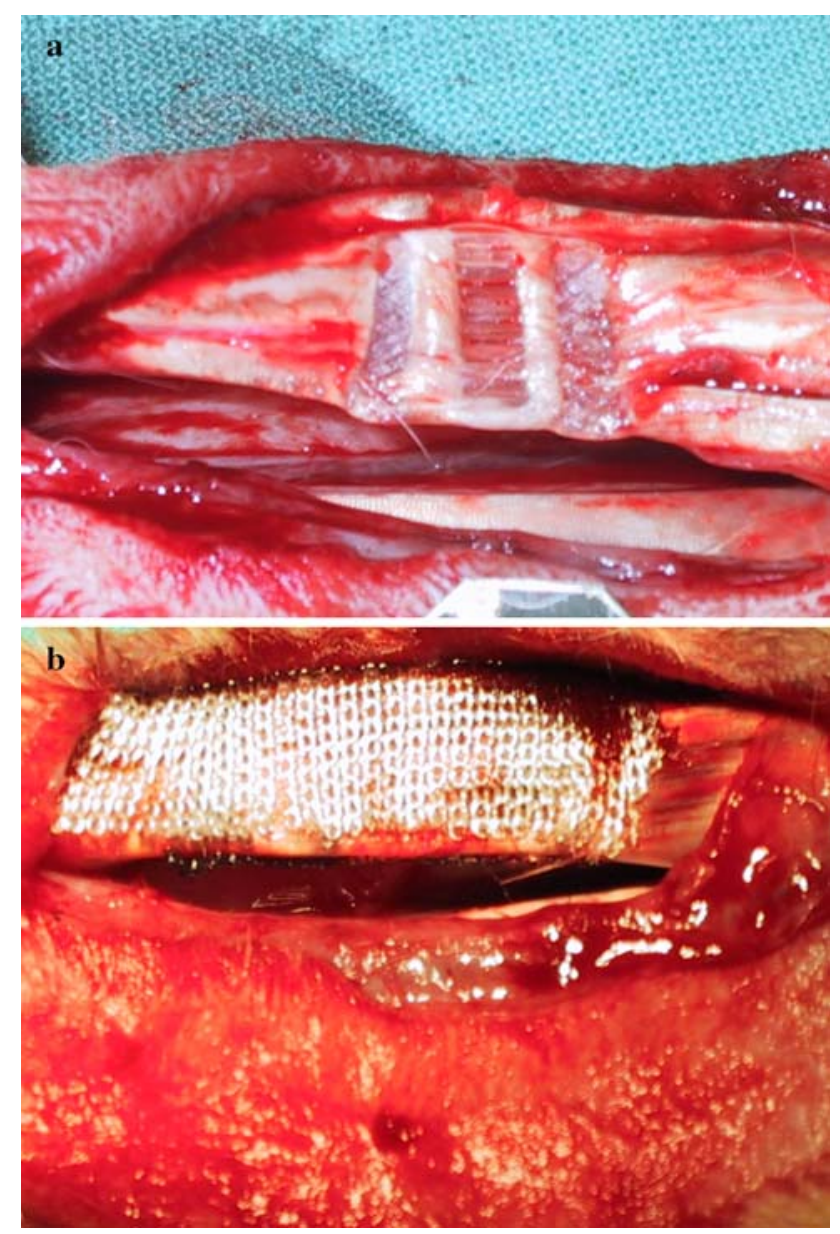

Fig. 1 a Rabbit tendo-achilles after crushing by three Kocher forceps for $20 \mathrm{~min}$. b The crushed tendo-achilles enclosed by a sheet of Divide $^{\circledR}$ 
a crushing injury. The right lower limb served as the experimental limb, while the left was designated as the control limb. The crushed zone of the right Achilles tendon was enclosed by a sheet of Divide ${ }^{\circledR}$ (Fig. 1b). The skin incisions were then closed with a running 3-0 Ethilon suture. The rabbits were caged without immobilisation and were on a 12-hour day/night cycle. Standard laboratory food and water were provided ad-libitum.

Functional and histological evaluation About 15 rabbits were used for functional and histological evaluation. Six weeks post-operatively, they underwent a functional evaluation under anaesthesia to determine the range of motion at the ankle. The knee was immobilized in neutral position with a K-wire. An $80 \mathrm{~g}$ load was suspended from the foot and a mechanical goniometer used to measure the range of motion at the ankle on both lower limbs. At the end of this evaluation, both Achilles tendons and their sheaths were removed en bloc and placed in formalin. Serial histological section were made and stained with $\mathrm{H} \& \mathrm{E}$. These were evaluated microscopically by an independent anatomopathologist for the quality of the tendon and type of adhesion tissue present.

\section{Biomechanical study}

About 13 rabbits were used for the biomechanical study. This study was necessary to ensure that Divide ${ }^{\circledR}$ did not modify mechanical qualities of the tendon. This test was carried out on an extension measuring table. Six weeks post-operatively, the tendons were removed en bloc and directly immersed in physiologic saline solution. A test of elongation was applied to the tendon with traction of $100 \mathrm{~N}$ at two different speeds ( 30 and $10 \mathrm{~mm} / \mathrm{min}$ ) in order to cover the various physiological conditions of the tendon. The same protocol was applied on a human deep flexor tendon preserved under the same conditions.

Morphological (SEM) study This third arm of the experimental study was designed to examine the biological relationship of the crushed tendon with the surrounding soft tissue, and to determine the moment of resorption of the Divide ${ }^{\circledR}$. About 18 rabbits were used for this arm. The Achilles tendon was removed on days 2, 4, 6,8 , and 10 after the surgical procedure. The tendon surfaces were examined under a scanning electron microscope.

\section{Clinical study}

The results of experimental study demonstrated that Divide ${ }^{\circledR}$ was biocompatible and resorbed completely. In addition, the absence of local or systemic complications and the presence of functional improvement enabled us to get the go-ahead from the Research Ethics Committee for an evaluation of Divide ${ }^{\circledR}$ in humans. The purpose of the clinical study was to assess the ability of Divide ${ }^{\circledR}$ to prevent post-surgical adhesions of the extensor system of the wrist and fingers following surgery in patients with rheumatoid arthritis and patient requiring tenolysis after injury to the extensor tendons respectively. The endpoint was to note the change in total active motion (T.A.M.) before surgery till the 12 th post-operative week.

\section{Patients and methods}

About 22 patients were operated between August 2003 and June 2005 by the same surgeon (M.M.). This included 14 men and 8 women with an average age of 55.5 years (18-74 years). Of these, six patients were in the rheumatoid arthritis group and 16 were in the tenolysis group. This was a single centre open label, nonrandomised, non-controlled assessment of the ability of Divide $^{\circledR}$ to prevent post-surgical adhesions of the extensor system of the fingers and wrist. The patients were operated under general or local anaesthesia. In the arthritis group, the patient underwent synovectomy of the wrist extensor tendons, while in the other group, the main surgical procedure was tenolysis. If necessary others surgical procedures (arthrolysis, arthroplasty, etc.) were performed. The insertion of the sheet of Divide ${ }^{\circledR}$ was easy. The trimming was neat and its adhesiveness to the tissue bed did not require any fixing by suture. Otherwise, it is advisable to carry out a careful hemostasis because the imbibition of Divide ${ }^{\circledR}$ by blood makes it ineffective. The Divide ${ }^{\circledR}$ sheet was placed between bone and tendon, skin and tendon or between tendons. The patients were evaluated preoperatively and postoperatively on days 0,3 , 8 and weeks 3, 6, 12. Evaluation consisted of measurement of the T.A.M., which was determined by adding the active range of motion at the metacarpo-phalangeal, proximal inter-phalangeal and distal inter-phalangeal joints and subtracting the lack of extension at these joints [6]. The T.A.M. in a normal individual is $260^{\circ}$. In order to take into account the effect of tenodesis due to wrist motion, the amplitude of wrist motion was also recorded at every evaluation. In addition, a Jamar dynamometer was used to measure grip strength.

\section{Statistical analysis}

A treated digit was defined as a digit that received treatment on any part of the digit. Change in T.A.M. was 
expressed as a percentage of $260^{\circ}$ (the normal score) and categorised into three groups;

1. Failure $(<+15 \%$ change $)$.

2. Improvement ( $+15 \%$ to $+75 \%$ change).

3. Significant improvement $(>+75 \%$ change).

Confidence intervals (95\%) of T.A.M. were presented by patient group and overall for the continuous variables, while for the discrete variables no analysis was carried out and only summaries are presented (by patient group and overall). Statistical analysis was carried out using SAS Version 9.1.3 (SAS Institute Inc. Cary, NC, USA).

\section{Results}

\section{Experimental study}

\section{Functional study}

Four out of the 15 rabbits died during the surgical procedure. No operative or post-operative complications (inflammatory reaction, infection, and haematoma) were noted in the remaining 11 rabbits. The time taken for wound healing was the same on both lower limbs. The biocompatibility of Divide ${ }^{\circledR}$ was excellent. Figure 2 compares the range of motion between the control and experimental limbs. All the points [7] situated above the

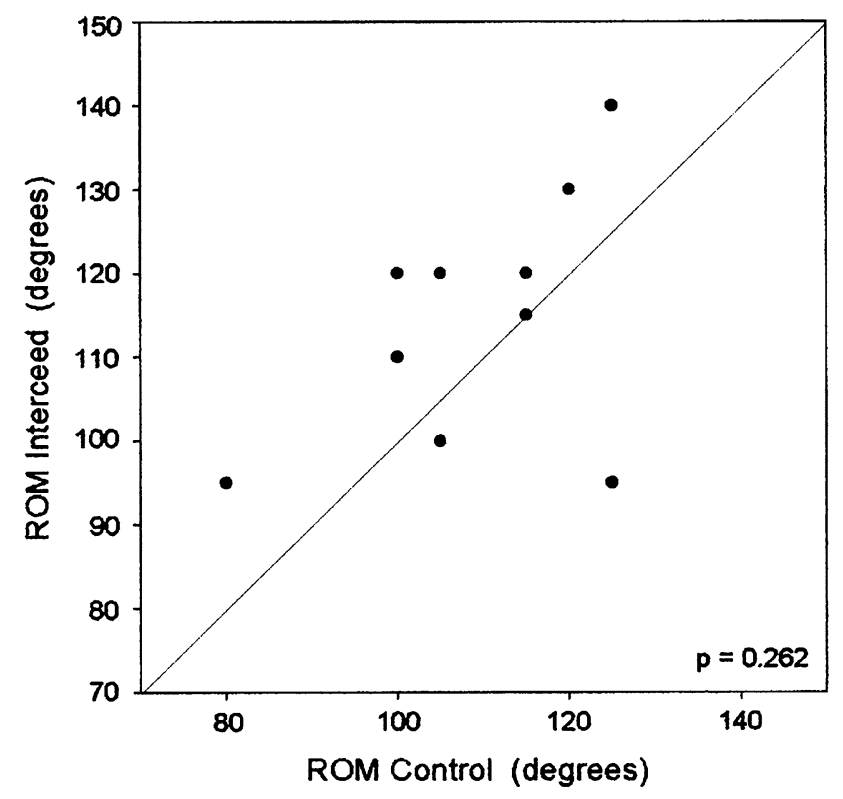

Fig. 2 Range of motion (ROM) of the ankles in 11 operated rabbits. The seven points above the oblique line correspond to the amplitudes of tendons treated with Divide ${ }^{\circledR}$. The two points below the same lines represent amplitudes in the operated group that are inferior to their controls. The two points on the line represent those that have the same amplitude as their controls line represent the number of rabbits treated with Divide ${ }^{\circledR}$, which have a higher useful area of mobility than the rabbits in the control group. Conversely, all the points [2] below the line represent the control group. The points [2] situated on the right hand line mean that there is no difference between a tendon treated with Divide ${ }^{\circledR}$ and the contralateral tendon use as a control. Two animals showed no difference between the two limbs, while in two rabbits, the range of motion was better in the control group. In seven rabbits, the results were better for rabbits treated with the Divide ${ }^{\circledR}$ mesh. Although this difference was not statistically significant $(P \leq 0.262)$ due to the limited number of animals operated on, it was clear that mobility was improved in the group treated with Divide ${ }^{\circledR}$.

\section{Histological study}

Histological examination showed that the quality of the tendon repair was better on the experimental side (Fig. 3). The control group showed a significant peri-tendinous fibroblastic reaction with adhesions to the paratenon, explaining the deterioration in gliding capacity (Fig. 4). The side treated with Divide ${ }^{\circledR}$ had fewer adhesions and a better delineation of the tendon sheath. The peri-tendinous surface was regular and only a mild disorganisation of the intra-tendinous structure was noted. A discrete peri-tendinous fibroblastic surface, induced by the sheet of Divide ${ }^{\circledR}$ was seen. However quantification of fewer adhesions proved to be impossible on histological cuts.

\section{Morphological study (Scanning Electron Microscope)}

Examination of the tendon sheath under the scanning electron microscope showed that the tendon sheath

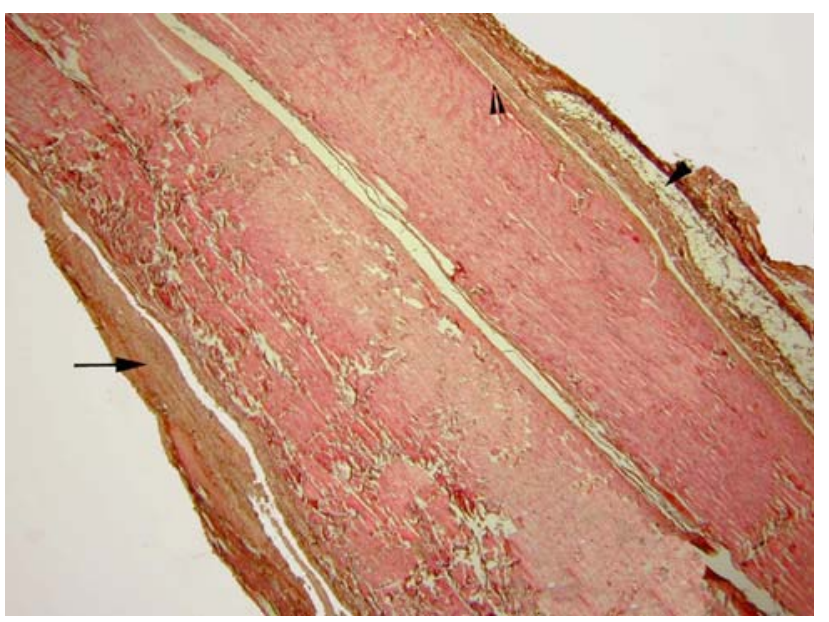

Fig. 3 Histological appearance of a tendon treated with Divide ${ }^{\circledR}$. The arrow shows the formation of the pseudosheath. The open arrow indicates the peri-tendon and the full arrow adipocytes in the pseudosheath. The tendon surface is smooth facilitating gliding 


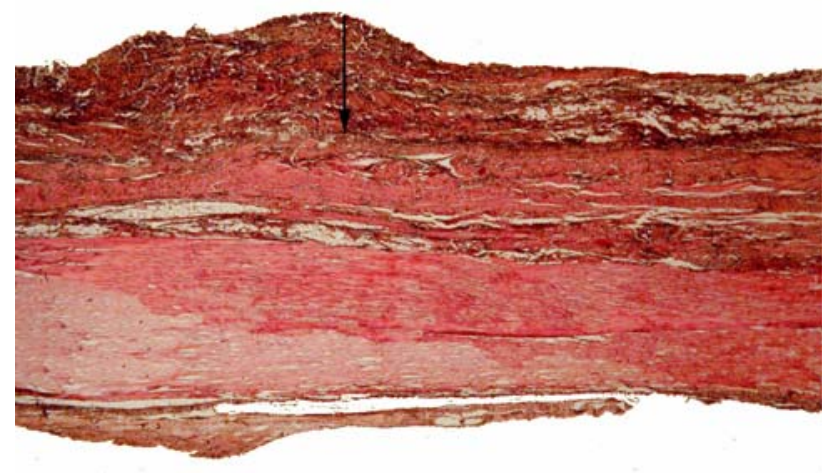

Fig. 4 Histological appearance of the control tendon. The arrows show that the hyperplastic reaction of the crushed tendon without formation of the pseudosheath which is however present on the opposite side

remained unchanged on both sides during the first six postoperative days. Between the sixth and the tenth days, an inflammatory reaction resulting in an effusion of synovial fluid due to the resorption of the sheet of Divide ${ }^{\circledR}$ was observed. We also noted some difficulty in removing the sheath on the eighth day. The consistency of the sheath was similar to that of the gelatine and scanning electron microscopy was impossible. By the tenth day, a new sheath was observed around the tendon. A few collagen fibres were present, but the sheath had not completely formed (Fig. 5).

\section{Biomechanical study}

About 12 rabbit tendoachilles were subjected to traction of $100 \mathrm{~N}$, at a velocity of $30 \mathrm{~mm} / \mathrm{min}$ and six at a velocity of

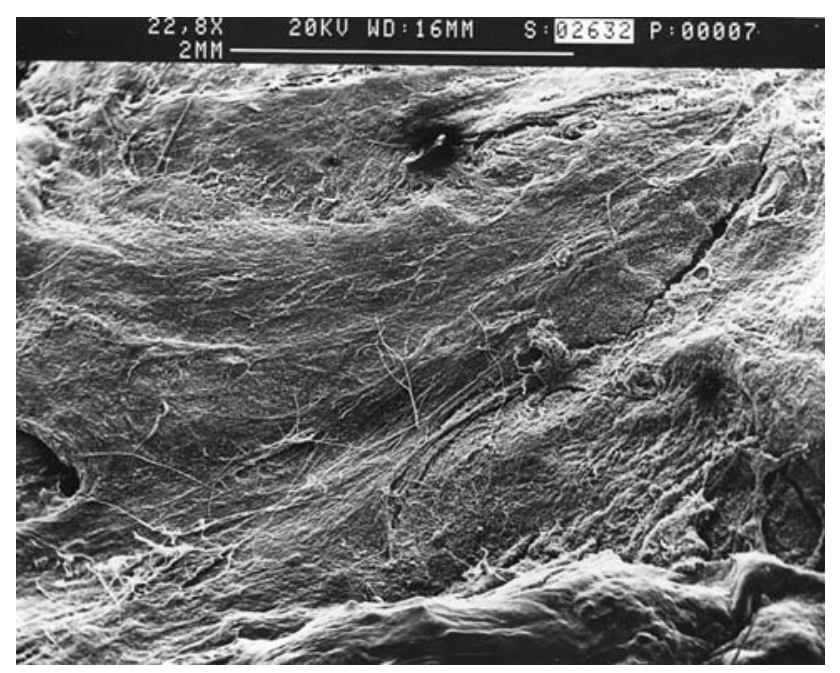

Fig. 5 Scanning electron microscopic image of the tendinous surface treated with Divide ${ }^{\circledR}$ on the 10th post-operative day. At this stage, the sheet of Divide ${ }^{\circledR}$ has liquefied revealing a smooth tendon surface
$10 \mathrm{~mm} / \mathrm{min}$. None of the tendons lengthened more than $0.1 \mathrm{~mm}$. The site of elongation in both groups was the same, as shown by the slope of the graphs in Fig 6a,b. One of the difficulties of this test resided in the quality of the fixation of the tendon extremities in the jaws of the extensometer. This explains why in 12 comparative measurements of right (Divide ${ }^{\circledR}$ ) and left (control) side, the slopes of the curves are similar, whereas in six others there is a drift due to slippage of the tendon. Finally, the study of the elongation of a human deep flexor tendon showed that its mechanical characteristics were similar with those of the tendon of Achilles of rabbit (Fig. 7).

a

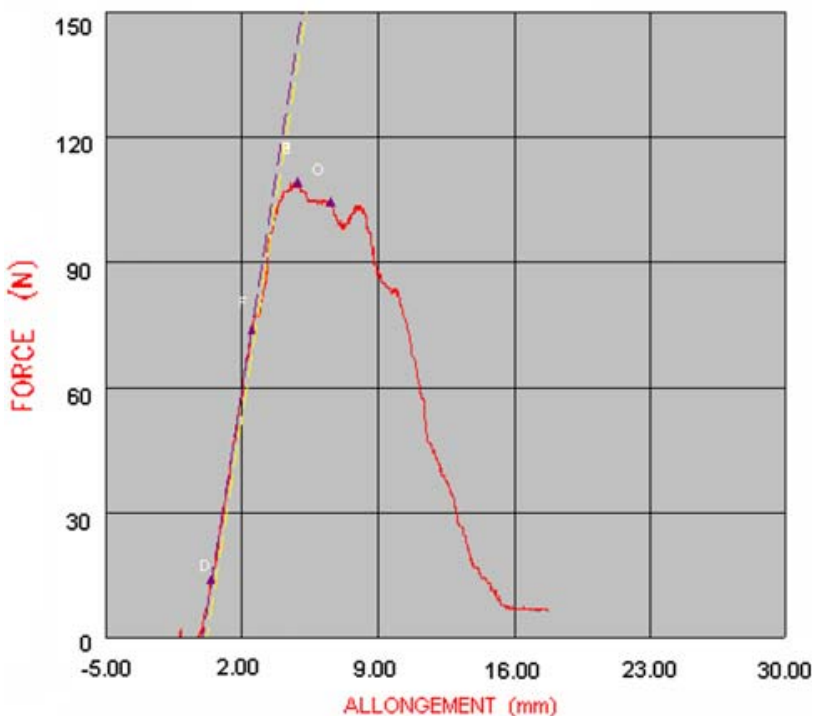

b

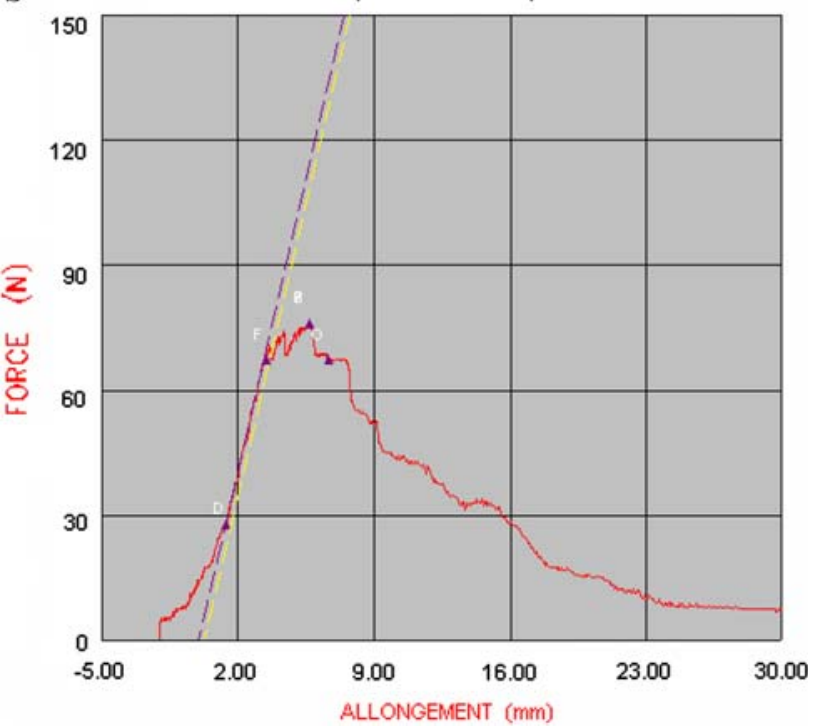

Fig. 6 a The mechanical characteristic of the tendon treated with Divide ${ }^{\circledR}$ subjected to stress testing is represented by the slope between points $\mathrm{D}$ and $\mathrm{F}$ 


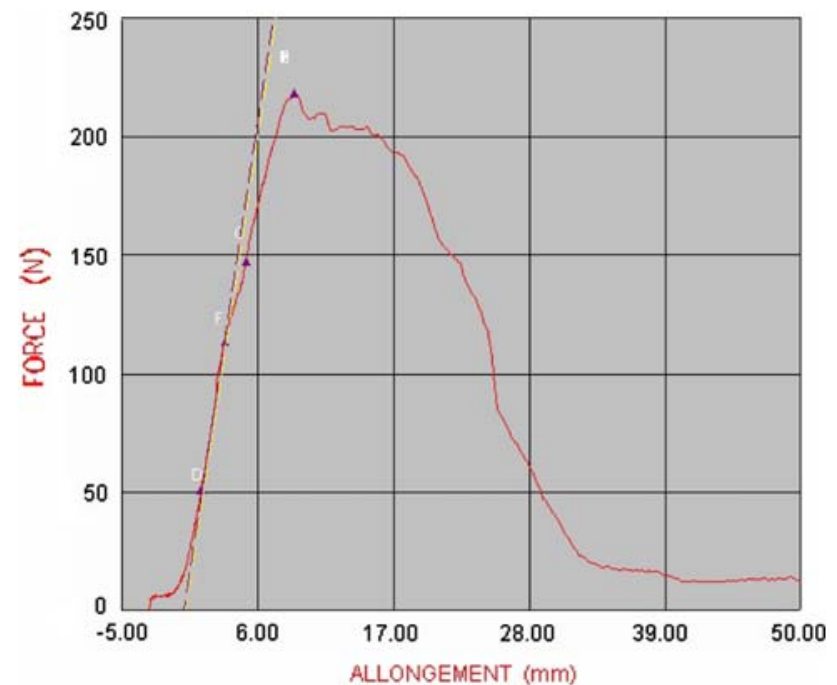

Fig. 7 There is no significant difference between the control tendon $6 \mathrm{~b}$ and the human tendon

\section{Clinical study}

\section{Tenolysis group}

Out of the 16 patients, 15 completed the study, while one was lost to follow-up. The mean age in this group was 41.6 years (range 18-68years), mean height $173 \mathrm{~cm}$ (range $155-186 \mathrm{~cm})$ and mean weight $76.9 \mathrm{~kg}$ (range $57-110 \mathrm{~kg}$ ). About $81 \%$ of patients were employed and $75 \%$ of the patients were right handed and $56 \%$ underwent surgery on the right side. General anaesthesia was used in two cases, and local in the remaining 14 cases. The tissue bed was scarred in all patients and in $75 \%$, the tissue beds were highly scarred. Arthrolysis of the MCPJ was needed in $37 \%$ of patients; PIPJ in $69 \%$ and DIPJ in $25 \%$ of patients. A PIPJ arthroplasty was done in one patient. The Divide ${ }^{\circledR}$ sheet was placed in relation to bony structures in $69 \%$ of patients; tendons in $44 \%$ and surrounding tendons in $31 \%$ patients.

Post-operative inflammation was present in $71 \%$ of cases. Most patients improved, and by the 84th pos-operative day, only one patient (8\%) had inflammation. Inflammation refers to the usual reaction of the skin after an extensive dissection necessary to realise the tenolysis. It is not to be confused with an inflammatory reaction to foreign body which was not observed in this study. Postoperatively, haematomas were seen in $21 \%$ of cases. All haematomas resolved by day 21 . In one patient ( $8 \%$ ), a new haematoma was noted on day 84 .

A total of 16 digits were treated leaving 64 untreated digits. Preoperatively the mean T.A.M for each treated digit ranged from $70^{\circ}$ (thumb) to $193^{\circ}$ (little finger), with an overall mean of $159.4^{\circ}$ for the 16 treated digits. At the

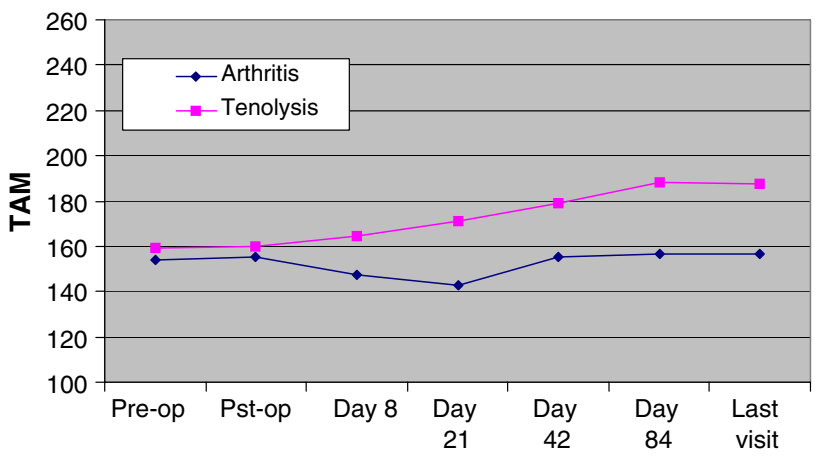

Fig. 8 Evolution of T.A.M. in both groups. One can observe that in the tenolysis group, a regular progress of amplitude of joint motion. In the rheumatoid arthritis group, the return of T.A.M. to pre-operative levels was at the sixth week, even though synovectomies usually give rise to joint stiffness

last visit (day 84 or the last visit recorded), T.A.M. had increased to $187.3^{\circ}$, an increase of $20.3^{\circ}$ (Fig. 8). In the untreated digits, the average pre-operative T.A.M. was $200.8^{\circ}$ (41.4 $4^{\circ}$ higher than for the treated digits), and increased to $209.4^{\circ}$ at the last visit. At the last visit, the treated digits achieved $72 \%$ of maximal T.A.M. $\left(260^{\circ}\right)$, compared to $81 \%$ for the untreated digits. The change to the last visit was not significant $(P \leq 0.074)$.

The strength was, on average, lower in this group when compared to contra-lateral hand throughout the study. The grip strength was on an average $26.7 \mathrm{kgF}$ lower than the contralateral hand pre-operatively and improved to $10.7 \mathrm{kgF}$ lower than the contralateral hand post-operatively (Fig. 9). The pinch strength measurements however, remained between 0 and $5 \mathrm{kgF}$ below that of the contralateral hand throughout the study (Fig. 10).

\section{Arthritis group}

All six patients in this group completed the study. The mean age was 66.8 years (range 53-74 years), mean height $163 \mathrm{~cm}$ (range 160-166 cm) and mean weight $60.0 \mathrm{~kg}$ (range $47-68 \mathrm{~kg}$ ). About $50 \%$ of the patients were

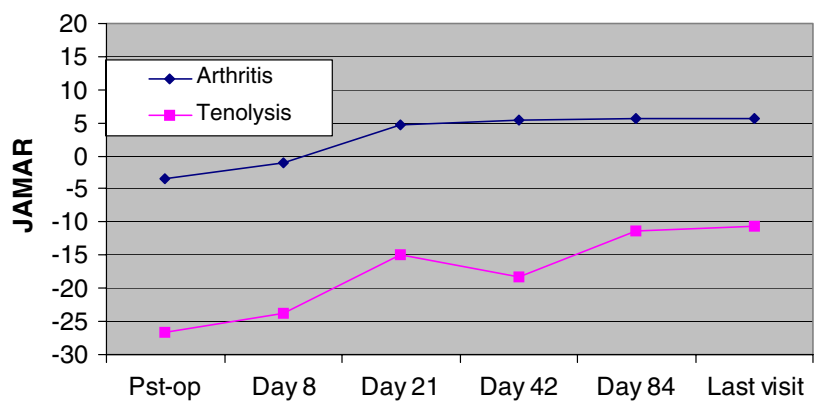

Fig. 9 Grip strength measured with a Jamar dynanometer showed a regular progress in both clinical groups with a mild regression in the sixth week for the rheumatoid arthritis group 
Fig. 10 a Stiffness in extension of the finger after a crushing injury complicated by an unrepresented haematoma. b After an extensive synovectomy, a sheet of Divide ${ }^{\circledR}$ is interposed between the periosteum and the extensor apparatus. c,d Full function after 3 months
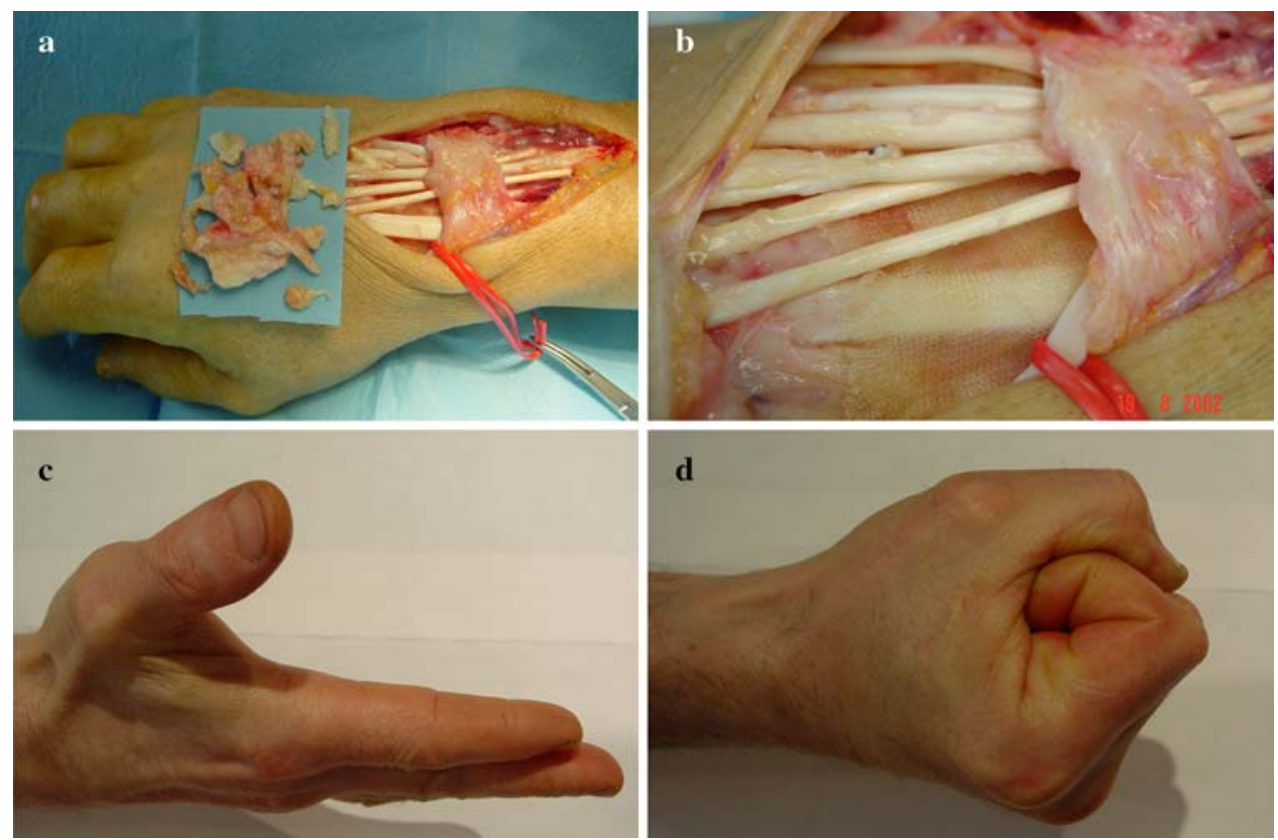

employed. The right hand was dominant in all patients and $67 \%$ underwent surgical procedures on the right side. The surgery was done under general anaesthesia in one patient and using local anaesthetic in the remaining five patients. One $(17 \%)$ tissue bed was normal $(17 \%)$, but most $(50 \%)$ were highly scarred. Arthrolysis of the wrist was needed in one patient (17\%); MCPJ in one patient (17\%) and PIPJ in two patients (33\%). No arthrodesis or arthroplasty were needed. The Divide ${ }^{\circledR}$ sheet was placed in relation to the bony structures in $83 \%$, between the skin and tendon in $\%$ and surrounding the tendons in $17 \%$.

Post-operative inflammation was present in $17 \%$ of cases, rising to $50 \%$ by day 8 . By day 84 no patients had inflammation. A haematoma was present in $33 \%$ of cases and all resolved by day 21 . There was no case of allergic reaction.

There were a total of eight treated digits, and hence 22 untreated digits. Pre-operatively the mean T.A.M. for each treated digit ranged from $80^{\circ}$ (digit 1 , thumb) to $175^{\circ}$ (digit 3 ), with an average of $153.8^{\circ}$ for the eight treated digits. At the last visit, the average T.A.M. had increased slightly to $156.3^{\circ}$, an increase of $2.5^{\circ}$ (Fig. 8). In the untreated digits, the average pre-operative T.A.M. was $173.9^{\circ}\left(20.1^{\circ}\right.$ higher than for the treated digits) and increased by $17-190.9^{\circ}$ at the last visit. At the last visit the treated digits were at $60 \%$ of maximal T.A.M., compared to $73 \%$ for the untreated digits. The change to the last visit was not significant $(P \leq 0.889)$ (Fig. 8).

There was little difference between the pre-operative strengths between the operated and un-operated sides, hence little chance for improvement. The extension grasp strength was on an average $3.4 \mathrm{kgF}$ lower than the contralateral side pre-operatively and improved to $5.7 \mathrm{kgF}$ greater than the contralateral side by the 84th post-operative day (Fig. 9). The pinch strength was $2.4 \mathrm{kgF}$ lower than the contralateral side pre-operatively and improved slightly to $2.5 \mathrm{kgF}$ greater than the contralateral side at the last visit.

The difference in T.A.M. between the arthritis and the tenolysis groups was not significant (20.3 vs. 2.5, $P \leq 0.361$,). The change to the last visit for both the tenolysis group $(+20.3)$ and the arthritis group $(+2.5)$ were not significant $(P \leq 0.074$, statistical output $1 ; P \leq 0.889$, statistical output 2 , both $t$-test).

\section{Discussion}

\section{Experimental study}

The amplitude of motion at the experimental ankle was noted to be higher in $63.7 \%$ of cases. However there were not enough rabbits to show significance in this part of the study $(P \leq 0.262)$. The histological study demonstrated that the peri-tendinous envelope created by Divide ${ }^{\circledR}$ helps in the structural reorganisation of the tendon and induces, after resorption, a fibroblastic layer facilitating gliding. It is however difficult to determine the mechanism of action of Divide $^{\circledR}$ with respect to decreasing tendon adhesion formation and facilitating the reorganisation of the tendon structure. It is probable that the sheet of Divide ${ }^{\circledR}$ transformed into a gelatinous barrier supporting synovial flow around the tendon. It is interesting to observe that the fast resorption of the Divide ${ }^{\circledR}$ does not induce inflammatory 
reaction to foreign body. This characteristic of oxidized cellulose is in contrast to fast resorbing polymers like polyglycolic acid (PGA) derivatives, whose resorption results in marked inflammatory reaction [4].

The evaluation under the scanning electronic microscope (SEM) is only morphometric and does not allow correlation of the appearance of the tendon with its function. It is interesting to observe that the surface of the Achilles tendon treated with Divide ${ }^{\circledR}$ is practically identical to that of a normal tendon, whereas the control tendon presents an amorphous surface (Fig. 5). The manufacturer announces a total resorption of Divide ${ }^{\circledR}$ within three weeks; however we were not able to make an SEM study until the eighth post-operative day. This period corresponds to a total transformation of the sheet of Divide ${ }^{\circledR}$ and probably explains our technical failure. This fast resorption however allows the induction of a gliding surface as shown in the histological study, but the process of tendons healing is not complete. Gelberman et al. [7] showed that the initial phase of inflammatory response (lasting upto day 8) is followed by a phase of fibroblastic proliferation (lasting for three weeks) and then by a phase of maturation of the collagen (lasing until the eighth week). This probably explains the partial functional results and even the two failures because the sheet of Divide ${ }^{\circledR}$ reabsorbs quickly. The ideal would be to have a resorbable biomaterial which accompanies in totality the healing process.

No inflammatory or allergic reaction to Divide ${ }^{\circledR}$ was seen in this experimental series. In addition, its application around the tendon did not modify the tendon's biomechanical characteristics as shown by the extension test done at the sixth week.

\section{Clinical study}

An improvement in T.A.M. by an average of $20.3^{\circ}$ resulting in an increase of motion of $72 \%$ of maximum was seen in the tenolysis group. Figure 8 shows a quasi-linear progression of the amplitudes, whereas classically we observe stagnation or even regression of the amplitudes between the fourth and sixth post-operative weeks corresponding to the maturation of collagen [7]. This observation substantiates the inductive effect of a gliding surface by Divide ${ }^{\circledR}$. Stanley [8] also observed that early rehabilitation of patients was less painful when Divide ${ }^{\circledR}$ had been used; the gelatinous structure facilitating an early mobilisation. In the arthritis group, there was a minor improvement in T.A.M. of $2.5^{\circ}$, resulting in an increase of motion of $60 \%$ of maximum. In this small group of six patients, we observed that the recovery of the pre-operative amplitudes was complete by the 12th week, whereas it is traditional to observe stiffness after any extensive synovectomy. Of course, these patients are often under corticoids which limit the post-operative inflammatory reaction, but the contribution of Divide ${ }^{\circledR}$ allowed them a rapid return of their function.

In the tenolysis group, at baseline, there was a large difference $(26.7 \mathrm{kgF})$ between the grip strength in the (weaker) operated side, and the contra-lateral hand. The grip strength improved at the end of the study, although the final average difference was only $10.7 \mathrm{kgF}$. We noted a reduction in the grip strength between the third and sixth post-operative weeks, whereas the amplitudes continued to progress. This corresponded to the phase of fibroblastic proliferation. In the arthritis group, the treated and untreated hands had similar pre-operative strengths and there was little improvement in either measure. Finally, there were only two adverse events on each treatment and there were no safety concerns.

Since 1990s the use of an absorbable adhesion barrier prepared by the oxidation of regenerated cellulose has been used successfully in gynaecological and laparoscopic surgery [5]. Diamond et al. [9] increased the effect of this biomaterial by adding heparin. In a study applying Divide ${ }^{\circledR}$ to the sciatic nerve of rabbits, Ikeda et al. [10] showed the conservation of the properties and the function of the nerve. The addition of hyaluronic acid has been shown improve results [11]. In ophthalmic surgery, the combination of Divide ${ }^{\circledR}$ and 5-fluoroucaril facilitated the correction of an experimental strabismus in the rabbit [12]. Meislin et al. [13] carried out an experiment in the rabbit by evaluating adhesions after partial tenotomy of the Achilles tendon. The tendon was sutured and the rabbit leg immobilised. They showed mechanically and histologically that the interposition of an oxidized regenerated cellulose sheet significantly decreased the extent and the number of adhesions. Loick et al. [14] used Divide ${ }^{\circledR}$ to reduce the risk of post-operative compression of the median nerve in the carpal tunnel.

Termiz et al. [15] in a series of 23 rats enveloped repaired tendons with Interceed ${ }^{\circledR}$. They observed that the enveloped tendons had no adhesions in 11 rats $(47.8 \%)$ and mild adhesions in 12 rats $(52.2 \%)$. In contrast, the unenveloped tendons showed mild adhesions in two rats $(8.6 \%)$, moderate adhesions in 15 rats $(62.5 \%)$ and severe adhesions in six rats $(26.2 \%)(P \leq 0.05)$. The mechanism of action of Divide ${ }^{\circledR}$ was studied by Reddy et al. [16] in the mouse and they concluded that the interaction of oxidized regenerated cellulose with macrophages with scavenger receptors may result in a decreased secretion of matrix components, inflammatory mediators, and cellular growth factors. Thus Interceed ${ }^{\circledR}$ cellulose may function as a biologic barrier in preventing adhesions. This approach confirms that the formation of peri-tendinous adhesions after treatment of the lesion is directly related to the proliferation of fibroblasts in the synovial sheath by the 
production of cytokines. The repair of a flexor rabbit tendon infiltrated by TGF-béta1 antibodies showed a functional result superior to the control tendon. This antibody reduces the fibroblastic reaction and the formation of adhesions. It is by assembling these various anti-adhesion activities that we will be able to further increase the quality of results of tendon surgery. One of the current challenges is to impact the process of tendon healing in totality. Divide $^{\circledR}$ reabsorbs as early as the eighth day and hyaluronic acid resorbs within 3-4 days.

Even though it is difficult to extrapolate results to repair in human, this study does validate the efficacy of absorbable adhesive barriers. The accumulation of this experimental and clinical work has enabled us to define the indications for the use of Divide ${ }^{\circledR}$ in hand surgery. All extensor and flexor tenolysis, with the exception of Zone 2 flexor, would benefit from Divide interposition. With experience, we have come to prefer a complete wrap around of the tendon, especially when the skin is scarred. In surgery for rheumatoid arthritis, wrapping of the tendon is done routinely after intercarpal synovectomy, and extensor tendon synovectomy. We have also extended the indication of Divide ${ }^{\circledR}$ to tendon transfer in post traumatic paralysis, when the tissue environment is often not conducive to tendon gliding. Finally, when the skin is of good quality, we utilise Divide ${ }^{\circledR}$ to prevent adhesion between bone and the extensor apparatus.

\section{Conclusion}

We found that Divide ${ }^{\circledR}$ is a biocompatible, biodegradable and non-allergenic material. It is resorbed by the $8^{\text {th }}$ day following a weak macrophagic reaction. This reaction produces a gliding surface and limits adhesion formation. The sheet of Divide ${ }^{\circledR}$ is easy to cut, its placement does not require any fixation and it allows early mobilisation. The use of Divide ${ }^{\circledR}$ mandates rigorous attention to haemostasis. Divide $^{\circledR}$ is particularly indicated in the surgery of the extensor tendons and flexor tendons apart from zone 2.

Open Access This article is distributed under the terms of the Creative Commons Attribution Noncommercial License which permits any noncommercial use, distribution, and reproduction in any medium, provided the original author(s) and source are credited.

\section{References}

1. Mainard D, Guth PC, Leroux P, Merle M, Michon J (1988) Comparaison expérimentale et clinique de trios biomatériaux pour la restauration du glissement tendineux en chirurgie de la main. In: Bénichoux R, Lacoste J (eds) Progrès récent des biomatériaux. Masson, Paris, France, pp 193-210

2. Merle M, Dautel G, De Medinaceli L (1995) Inhibition of peritendinous adhesion by ADCON-T/N in a rabbit flexor tendon model. 6th congress of IFSSH Helsinki 3-7 July in abstract book Monduzzi Ed. Bologna, pp 1025-1028

3. Merle M, Foucher G, Egloff D (1996) Perineural Peritendinous and scar and adhesions-Treatment with has new antiadhesion barrier gel/freezing, ADCON-T/NR. In: Rehart S, Zichner L (eds) Hand Surgery. A current concept review, frankfurt International hand surgery Conference, november; Thieme Stuttgart 1997, pp $33-40$

4. Dimitrijevich SD,Tatarko M, Gracy RW, Linsky CB, Olsen C (1990) Biodegradation of oxidized regenerated cellulose. Carbohydr Res 15:247-256

5. Seifer DB, Diamond MP, DeCherney AH (1990) An appraisal of barrier agents in the reduction of adhesion formation following surgery. J Gynecol Surg 6:3-10

6. Stickland JW (2000) Development of flexor tendon surgery: twenty-five years of progress. J Hand Surg [Am] 25(2):214-35

7. Gelberman RH, Manske PR, Akeson WH, Woo SL-Y, Lundborg G, Amiel D (1986) Flexor tendon repair. J Orthop Res 4:119-128

8. Stanley J (personal communication)

9. Diamond MP, Linsky CB, Cunningham T, Kamp L, Pines E, De herney AH, Di Zerega GS (1991) Adhesion reformation: reduction by the use Interceed (TC7) plus Heparin. J Gynecol Surg $7: 1-6$

10. Ikeda K, Yamauchi D, Tomita K (2002) Preliminary study for prevention of neural adhesion using an absorbable oxidised regenerated cellulose sheet. J Hand Surg 7:11-14

11. Yeo Y, Ito T, Bellas E, Highley CB, Marini R, Kohane DS (2007) In situ cross-linkable hyaluronan hydrogels containing polymeric nanoparticles for preventing postsurgical adhesions. Ann Surg 245:819-824

12. Hwang JM, Chang BL (1999) Combined effect of Interceed and 5-fluorouracil on delayed adjustable strabismus surgery. $\mathrm{Br} \mathrm{J}$ Ophthalmol 83(7):788-791

13. Meislin RJ, Wiseman DM, Alexander H, Cunningham T, Linsky C, Carlstedt, Pitman M, Casar R (1990) A biomechanical study off tendon adhesion reduction using has biodegradable barrier in a rabbit model. J Appl Biomater 1:13-19

14. Loick J, Joosten U, Lucke R (1997) Implantation of oxidized, regenerated cellulose for prevention of recurrence in surgical therapy of carpal tunnel syndrome. Handchir Mikrochir Plast Chir 29(4):209-213

15. Temiz A, Ozturk C, Bakunov A, Kara K, Kaleli T (2007) A new material for prevention of peritendinous fibrotic adhesions after tendon repair: oxidised regenerated cellulose (Interceed), an absorbable adhesion barrier. Int Orthop., Mar 9

16. Reddy S, Santanam NR, Reddy PP, Rock JA, Murphy AA, Parthasarathy S (1997) Interaction of Interceed oxidized regenerated cellulose with macrophages: potential mechanism by which Interceed may prevent adhesions. Am J Obstet Gynecol 177(6):1315-1320; discussion 1320-1321 